\title{
Visual perception of the roundabout in old age
}

\author{
G. Fancello, C. Pinna \& P. Fadda \\ Department of Civil and Environmental Engineering and Architecture, \\ Cagliari University, Italy
}

\begin{abstract}
In recent years, the behaviour of older drivers has become one of the main objectives of safety research and much attention has been focused on the perception of the driver. Several studies have shown that mental and physical conditions, driving habits and behaviour when performing certain manoeuvres differ with age. The mental and physical faculties of over 65-year olds and their ability to concentrate behind the wheel deteriorate more rapidly, with the result that there is a greater likelihood of them having an accident. It is for this reason that research in later years has focused primarily on identifying active safety measures to assist older drivers, aimed at facilitating certain tasks and improving their performance, so as to avoid mishaps on the road. These measures concern above all restrictions and limits, support and assistance, redesigning the road system, and in-vehicle driving aids. In this paper we have analysed the behaviour of elderly drivers while they go through a roundabout: we investigated their visual perception during driving, to assess which elements help drivers to cross the roundabout, and which have bad influences during guide (distractor signals). To evaluate the drivers' perception we propose an index, based on frequency and length period observation, to assess stimulus generated by road: starting from Neisser Index, we propose an experimental index based on the complex structure of driver's vision. A mobile eye tracker has been used both to define which elements drivers use during roundabout crossing and to measure the time period perception of each road and traffic element. Eleven older drivers are tested on a suburban roundabout: also eleven young people were tested to compare the results. Results confirm that elderly drivers are concentrated only on traffic flow arriving from the right arm of the roundabout and the vehicle in front: other elements on the roundabout have no influence on drivers' behaviours.

Keywords: older drivers, roundabout, visual perception.
\end{abstract}




\section{Introduction}

Physical and medical conditions, sensory and cognitive functions of a driver are factors that influence the attitude to drive [1] and thus influence the likelihood of an accident [2]. Aging causes a decline in skills that are required for performance of complex tasks such as driving. This issue is of general interest because medical advances have led to an increase in average life expectancy: people older than 65 years are the fastest growing segment in the population and they continue to have a key role in society. This feature has a direct impact on their mobility needs, because they tend to leave the driving license later [3]. Drive a vehicle is still a way for the elderly to keep their independence and participate in social life, particularly in rural or remote areas where public transport is not suitable to their needs [4]. General data on injuries show that accident rates are higher for older drivers and increase exponentially over the age of 75 [5]. Accidents in which the elderly are involved are also characterized by a high level of damage due to the decline of their physical condition and the high rigidity of their skeletal system: the probability of being involved in a fatal accident increases from the 70 years age [3]:

- $\quad$ for drivers aged between 70 and 74 years the probability of death in an accident is double than drivers aged between 30 and 59;

- while for drivers with more than 80 years old the risk is five times higher [6];

- $\quad$ higher mortality rates are due to physical fragility that makes a simple accident, a potentially fatal event.

Vision is the ability more affected by aging and is the largest recipient of stimulus needed to drive [7, 8]. Visual impairments influence the probability of an accident $[9,10]$ and also affect the ability to identify and understand a signal or a visual stimulus [11]. Dobbs [12] identified some visual problems, typical of old age, which can be disabling for driving and impaired visual acuity, glaucoma, retinitis pigmentosa, cataracts, macular degeneration, diabetic retinopathy field and visual defects. In old age the eye is more sensitive to glare and increases the level of illumination needed to capture a visual stimulus [13, 14]: it causes a reduction of the visual field [15], and the focus for the different distances is adjusted slowly [16]. With aging also increases the minimum duration of fixation needed to identify the details characteristic of a signal [17]: in fact elderly drivers show poor performance of visual search in localization and signal reading and the scanning speed of the visual scene undergoes a marked slowdown [18]. A study by Owsley and Ball [19] showed that drivers with a reduction of the visual field are likely to be involved in an accident 15.6 times more than drivers with normal visual field. Accidents caused by elderly drivers often occur in early morning or late evening, due to low visibility [20]. Older drivers are in trouble in various traffic situations, particularly in the left turns [20], in intersections and in those regulated with the stop sign [21]; in fact, accidents involving elderly drivers happen mainly at intersections [22]. These 
particular situations, where there are many stimuli, are difficult to manage for elderly drivers, because of the number of operations to be performed crossing an intersection (vehicular and pedestrian flow control, evaluation of manoeuvring space etc.): these manoeuvres enclosed in reduced time, can cause a work overload for the driver and determine the decline of his mental and physical abilities, thus increasing the risk of error [23]. Older drivers are not all dangerous, but rather show a prudent behaviour and they compensate for their disadvantages physical with their experience [21], because age is a compensation of some abilities [24]. The objective of this study is to investigate the phenomenon of visual perception of an intersection roundabout by older drivers compared to some young people, and find a relationship that allows us to assess the complexity of perception of all the observed elements during drive task. Two groups of drivers have been selected: one formed by the elderly drivers and the other by young drivers, all have travelled in the same itinerary where is located a roundabout. For each one, using a portable eye-tracker, fixation times have been evaluated and the level of perception of the elements has been estimated; finally an analytical relationship has been calibrated.

\section{Methodology}

The study has involved 22 volunteer drivers: 11 elderly and 11 young people. The older drivers (named from 1 to 11) were 9 men and 2 women (generally older women tend to not renew a driver's license once they retire and 65 years of age reached). The older drivers tested were aged between 67 and 82 years and the average age of the sample was 72 years. $54.54 \%$ of the drivers have eye problems, but only $45.45 \%$ regularly wears glasses. $45.4 \%$ of drivers suffer from hypertension, while $18 \%$ have problems with high cholesterol and adult-onset diabetes (a disease with direct implications on the view), only 18\% do not have any general health problem. Young drivers (named from A to $\mathrm{M}$ ) were 8 men and 3 women, and they are aged between 24 and 47 years and the average age of the sub-sample is 33 years. None of the tested drivers presents general health problems and 4 of them have some slight ametropias, which are corrected with the use of glasses or contact lenses corneal. The tested intersection is a four-arm roundabout with a diameter of 40 meters, and the traffic level of service not less than B. It is located in a suburban area, chosen to avoid disturbing effects from congestion, or from pedestrians that might influence the perception of the roundabout geometry; the tests were conducted on weekdays, because the roundabout is located in an area that during the holidays is affected by significant tourism flow; moreover the tests were conducted on different days, always at the same time to avoid that the visual perception was affected by different light conditions. Each driver has used own car so that there was a strong familiarity with the vehicle, so distractions have been minimized. Tests of visual perception have been made using an "eye tracker" portable with two cameras synchronized: the first camera points the eye, to record pupil movements; the other camera looks the external environment observed by the driver: the synchronization allows us to see instantly what the eye sees and how long. This tool uses eye 
tracking technology called "Dark Pupil Tracking”. The data obtained from the registration were analysed with software "Gaze Tracker" which identifies the points or areas observed by the driver, and calculates the duration of the look: also allows us to define the movements of the eyes to different points of view, thus allowing the reconstruction eye movements. The drivers' visual field was divided into eight areas, named "look zones": previous vehicle, arm of the roundabout located to the left of the driver, arm of the roundabout located to the right of the driver, arm of the roundabout located in front of the driver, road signs, centre island, traffic inside the roundabout, exit arm of the roundabout. To analyse the output data a matrix was developed, where second by second, the look zones viewed are pointed: (1) means the look zone viewed in that second; (0) otherwise. Below is a matrix:

Table 1: $\quad$ Matrix to analyze the fixation times.

\begin{tabular}{|c|c|c|c|c|c|c|c|c|}
\hline & $\begin{array}{l}\text { Previous } \\
\text { vehicle }\end{array}$ & $\begin{array}{l}\text { Arm to } \\
\text { the left }\end{array}$ & $\begin{array}{l}\text { Arm to } \\
\text { the right }\end{array}$ & $\begin{array}{l}\text { Arm in } \\
\text { front }\end{array}$ & $\begin{array}{l}\text { Road } \\
\text { Signs }\end{array}$ & $\begin{array}{l}\text { Centre } \\
\text { Island }\end{array}$ & $\begin{array}{l}\text { Traffic } \\
\text { inside }\end{array}$ & $\begin{array}{l}\text { Exit } \\
\text { arm }\end{array}$ \\
\hline 0.10 .13 & 1 & 0 & 0 & 0 & 0 & 0 & 0 & 0 \\
\hline 0.10 .14 & 0 & 0 & 0 & 0 & 0 & 1 & 0 & 0 \\
\hline 0.10 .15 & 0 & 0 & 1 & 0 & 0 & 0 & 0 & 0 \\
\hline 0.10 .16 & 0 & 1 & 0 & 0 & 0 & 0 & 0 & 0 \\
\hline 0.10 .17 & 0 & 0 & 1 & 0 & 0 & 0 & 0 & 0 \\
\hline 0.10 .18 & 0 & 1 & 0 & 0 & 0 & 0 & 0 & 0 \\
\hline 0.10 .19 & 0 & 0 & 1 & 0 & 0 & 0 & 0 & 0 \\
\hline 0.10 .20 & 0 & 0 & 1 & 0 & 0 & 0 & 0 & 0 \\
\hline 0.10 .21 & 0 & 0 & 1 & 0 & 0 & 0 & 0 & 0 \\
\hline 0.10 .22 & 1 & 0 & 0 & 0 & 0 & 0 & 0 & 0 \\
\hline 0.10 .23 & 0 & 0 & 1 & 0 & 0 & 0 & 0 & 0 \\
\hline 0.10 .24 & 0 & 0 & 1 & 0 & 0 & 0 & 0 & 0 \\
\hline 0.10 .25 & 1 & 0 & 0 & 0 & 0 & 0 & 0 & 0 \\
\hline 0.10 .26 & 0 & 0 & 0 & 0 & 0 & 1 & 0 & 0 \\
\hline 0.10 .27 & 0 & 0 & 0 & 1 & 0 & 0 & 0 & 0 \\
\hline 0.10 .28 & 1 & 0 & 0 & 0 & 0 & 0 & 0 & 0 \\
\hline 0.10 .29 & 1 & 0 & 0 & 0 & 0 & 0 & 0 & 0 \\
\hline 0.10 .30 & 0 & 0 & 0 & 0 & 0 & 0 & 0 & 1 \\
\hline 0.10 .31 & 1 & 0 & 0 & 0 & 0 & 0 & 0 & 0 \\
\hline 0.10 .32 & 0 & 0 & 0 & 0 & 0 & 0 & 0 & 1 \\
\hline 0.10 .33 & 0 & 0 & 0 & 0 & 0 & 0 & 0 & 0 \\
\hline 0.10 .34 & 1 & 0 & 0 & 0 & 0 & 0 & 0 & 0 \\
\hline 0.10 .35 & 1 & 0 & 0 & 0 & 0 & 0 & 0 & 0 \\
\hline 0.10 .36 & 1 & 0 & 0 & 0 & 0 & 0 & 0 & 0 \\
\hline 0.10 .37 & 1 & 0 & 0 & 0 & 0 & 0 & 0 & 0 \\
\hline $\begin{array}{l}\text { Observation } \\
\text { time }\end{array}$ & 10 & 2 & 7 & 1 & 0 & 2 & 0 & 2 \\
\hline Value \% & $41,67 \%$ & $8,33 \%$ & $29,17 \%$ & $4,17 \%$ & $0,00 \%$ & $8,33 \%$ & $0,00 \%$ & $8,33 \%$ \\
\hline
\end{tabular}


So, the travel time of the roundabout has been transformed from continuous variable to discrete variable, thus defining the observation time for each zone. To compare the performance of several drivers who were tested, the observation times of each look zone were expressed as a rate of the total travel time of the roundabout.

\section{Data analysis}

Now we explore how older drivers perceive and drive on a roundabout intersection, so to understand how they deal with a driving condition difficult taking account also on influence of habits, or stereotypes.

To understand which elements drivers have considered more useful during guide we have measured observation times of the various look zones, shown in fig. 3, who are:

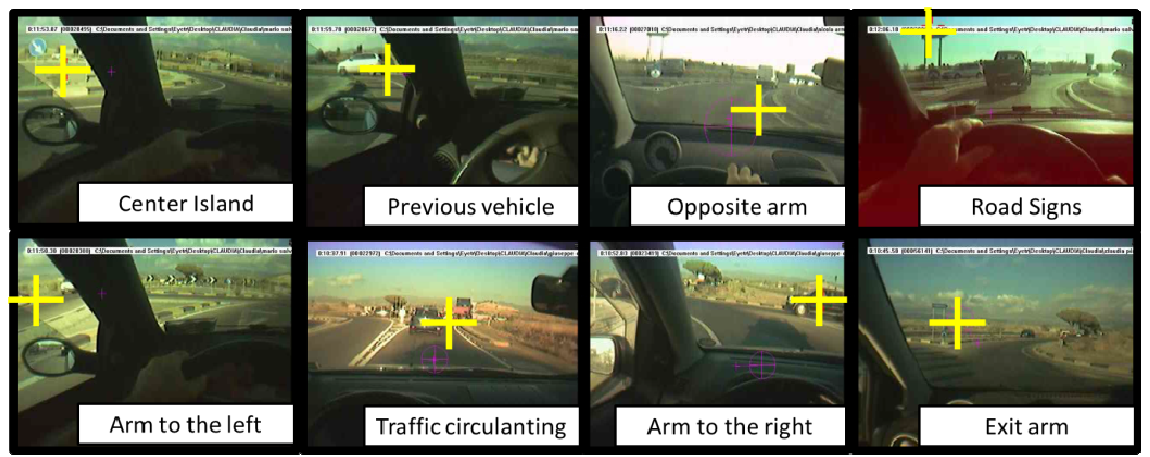

Figure 1: $\quad$ Look zones analyzed.

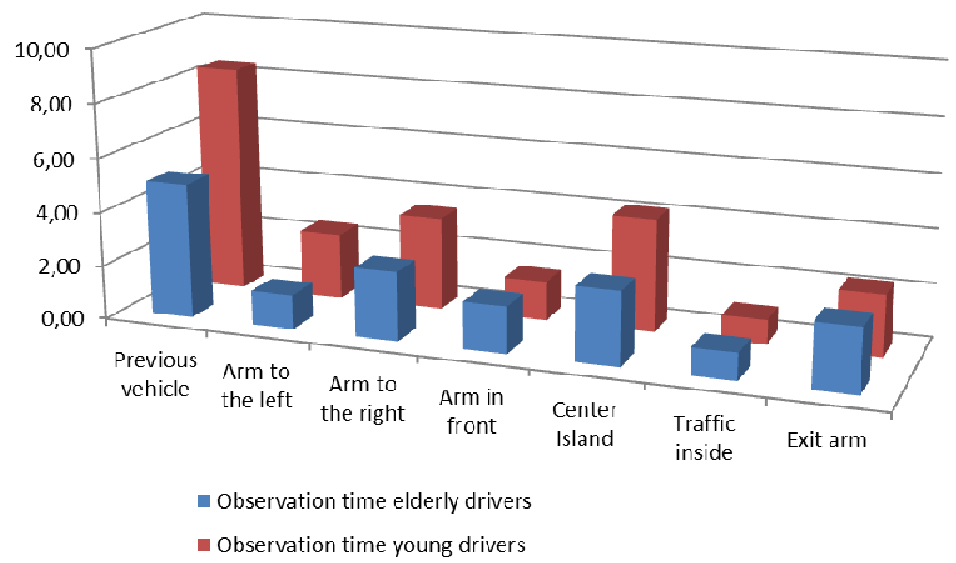

Figure 2: $\quad$ Observation times for the look zones analyzed. 
The main difference between the young and elderly drivers when crossing the roundabout is the speed of execution of the manoeuvre inside the roundabout. The average time to cross the intersection is $24.45 \mathrm{~s}$ for elderly drivers and 16.64 $\mathrm{s}$ for young drivers. With aging does not occur a remarkable loss of accuracy in the visual search of signals, but there is a slowdown of the processes involved [18]: in fact the fixation times needed to capture the different items of the roundabout are higher for drivers in old age. As shown by the above analysis, if we consider the observation times of the different elements of the roundabout expressed as a ratio with the total travel time of the intersection, there are no considerable differences among young drivers and the elderly.

Table 2 shows the observation times for the eight look zones, expressed as a rate of the total journey time of the roundabout.

Table 2: Percentage of observation of the different zones on the roundabout.

\begin{tabular}{|c|c|c|c|c|c|c|c|c|c|}
\hline & Drivers & $\begin{array}{c}\text { Previous } \\
\text { vehicle }\end{array}$ & $\begin{array}{l}\text { Arm to } \\
\text { the left }\end{array}$ & $\begin{array}{l}\text { Arm to } \\
\text { the } \\
\text { right }\end{array}$ & $\begin{array}{c}\text { Arm in } \\
\text { front }\end{array}$ & $\begin{array}{l}\text { Road } \\
\text { Signs }\end{array}$ & $\begin{array}{l}\text { Center } \\
\text { Island }\end{array}$ & $\begin{array}{l}\text { Traffic } \\
\text { inside }\end{array}$ & $\begin{array}{l}\text { Exit } \\
\text { arm }\end{array}$ \\
\hline \multirow{12}{*}{ 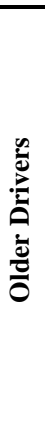 } & Driver 1 & $35,00 \%$ & $10,00 \%$ & $10,00 \%$ & $5,00 \%$ & $0,00 \%$ & $25,00 \%$ & $5,00 \%$ & $10,00 \%$ \\
\hline & Driver 2 & $34,62 \%$ & $19,23 \%$ & $11,54 \%$ & $0,00 \%$ & $0,00 \%$ & $15,38 \%$ & $3,85 \%$ & $15,38 \%$ \\
\hline & Driver 3 & $44,44 \%$ & $5,56 \%$ & $11,11 \%$ & $0,00 \%$ & $0,00 \%$ & $16,67 \%$ & $0,00 \%$ & $22,22 \%$ \\
\hline & $\begin{array}{l}\text { Driver } 4 \\
\end{array}$ & $42,31 \%$ & $7,69 \%$ & $3,85 \%$ & $15,38 \%$ & $0,00 \%$ & $15,38 \%$ & $7,69 \%$ & $7,69 \%$ \\
\hline & Driver 5 & $41,67 \%$ & $8,33 \%$ & $29,17 \%$ & $4,17 \%$ & $0,00 \%$ & $8,33 \%$ & $0,00 \%$ & $8,33 \%$ \\
\hline & Driver 6 & $45,71 \%$ & $8,57 \%$ & $5,71 \%$ & $5,71 \%$ & $0,00 \%$ & $20,00 \%$ & $0,00 \%$ & $5,71 \%$ \\
\hline & Driver 7 & $22,73 \%$ & $9,09 \%$ & $18,18 \%$ & $4,55 \%$ & $0,00 \%$ & $31,82 \%$ & $0,00 \%$ & $13,64 \%$ \\
\hline & Driver 8 & $15,00 \%$ & $20,00 \%$ & $35,00 \%$ & $15,00 \%$ & $0,00 \%$ & $5,00 \%$ & $0,00 \%$ & $10,00 \%$ \\
\hline & Driver 9 & $32,00 \%$ & $8,00 \%$ & $16,00 \%$ & $0,00 \%$ & $0,00 \%$ & $24,00 \%$ & $8,00 \%$ & $12,00 \%$ \\
\hline & Driver 10 & $47,62 \%$ & $14,29 \%$ & $9,52 \%$ & $4,76 \%$ & $0,00 \%$ & $14,29 \%$ & $4,76 \%$ & $4,76 \%$ \\
\hline & Driver 11 & $41,67 \%$ & $4,17 \%$ & $8,33 \%$ & $12,50 \%$ & $8,33 \%$ & $8,33 \%$ & $12,50 \%$ & $4,17 \%$ \\
\hline & Mean & $36,62 \%$ & $10,45 \%$ & $14,40 \%$ & $6,10 \%$ & $0,76 \%$ & $16,75 \%$ & $3,80 \%$ & $10,36 \%$ \\
\hline \multirow{12}{*}{ 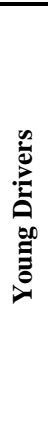 } & Driver A & $35,00 \%$ & $5,00 \%$ & $5,00 \%$ & $10,00 \%$ & $0,00 \%$ & $20,00 \%$ & $10,00 \%$ & $15,00 \%$ \\
\hline & Driver $B$ & $40,00 \%$ & $8,00 \%$ & $20,00 \%$ & $8,00 \%$ & $0,00 \%$ & $8,00 \%$ & $8,00 \%$ & $8,00 \%$ \\
\hline & Driver $C$ & $28,57 \%$ & $7,14 \%$ & $21,43 \%$ & $0,00 \%$ & $0,00 \%$ & $21,43 \%$ & $7,14 \%$ & $14,29 \%$ \\
\hline & Driver $D$ & $46,67 \%$ & $6,67 \%$ & $13,33 \%$ & $6,67 \%$ & $0,00 \%$ & $0,00 \%$ & $0,00 \%$ & $26,67 \%$ \\
\hline & Driver $E$ & $23,08 \%$ & $15,38 \%$ & $0,00 \%$ & $15,38 \%$ & $0,00 \%$ & $23,08 \%$ & $7,69 \%$ & $15,38 \%$ \\
\hline & Driver $F$ & $29,41 \%$ & $5,88 \%$ & $11,76 \%$ & $17,65 \%$ & $0,00 \%$ & $17,65 \%$ & $0,00 \%$ & $17,65 \%$ \\
\hline & Driver $G$ & $26,67 \%$ & $6,67 \%$ & $13,33 \%$ & $13,33 \%$ & $0,00 \%$ & $26,67 \%$ & $0,00 \%$ & $13,33 \%$ \\
\hline & Driver $H$ & $26,67 \%$ & $6,67 \%$ & $0,00 \%$ & $20,00 \%$ & $0,00 \%$ & $20,00 \%$ & $6,67 \%$ & $20,00 \%$ \\
\hline & Driver $I$ & & & $18,75 \%$ & $12,50 \%$ & $0,00 \%$ & $12,50 \%$ & $6,25 \%$ & $12,50 \%$ \\
\hline & Driver $L$ & $44,44 \%$ & $5,56 \%$ & $11,11 \%$ & $0,00 \%$ & $0,00 \%$ & $16,67 \%$ & $5,56 \%$ & $16,67 \%$ \\
\hline & Driver $M$ & $18,75 \%$ & $12,50 \%$ & $12,50 \%$ & $12,50 \%$ & $0,00 \%$ & $18,75 \%$ & $12,50 \%$ & $12,50 \%$ \\
\hline & Mean & $31,86 \%$ & $7,79 \%$ & $11,57 \%$ & $10,55 \%$ & $0,00 \%$ & $16,79 \%$ & $5,80 \%$ & $15,63 \%$ \\
\hline
\end{tabular}

Analysis of data shows that the element mainly observed is the vehicle in front, and that it has been seen by older drivers for $36.62 \%$ and by young people for $31.86 \%$ of total travel time of the roundabout. All drivers running through the roundabout often observe the centre island to set own vehicle path: in fact, the centre island has been seen by older drivers for $16.75 \%$ of the total time and by the young for $16.79 \%$ of the total time of fixation. The older drivers have looked 
more at the arm of the roundabout located on the right side than one located on the left, although they should give priority to traffic coming from the left side. In fact they have looked at the arm of the roundabout located on the right side for $14.40 \%$ of the total time and the arm on the left side for $10.45 \%$; moreover the young have less observed both arms, for $11.57 \%$ (right side) and for $7.79 \%$ (left side) of the total time of running across the roundabout. The young drivers have looked the arm of the roundabout which is on the opposite side for $10.55 \%$ of the time, but the elderly only for $6.10 \%$ of the time (three old drivers and two young drivers have never looked it). The elders have observed the arm to go out from the roundabout for $10.36 \%$ of the time, while young people for $15.63 \%$. The traffic flow inside the roundabout has been looked by older drivers or $3.80 \%$ of the time, and by the young for 5.8\%. Only one elderly driver has seen the road signs on the roundabout, to verify the way out of the roundabout. Road signs have been not observed by young drivers: it may be that they don't consider them as driver assistance, as also shown by previous analysis regarding the whole route. That is because within complex nodes as intersections (particularly roundabouts), there are too many stimuli that can't be perceived together, therefore drivers exclude some of them, such as road signs. Briefly, older drivers observed more than young the previous vehicle and the arms on the right and on the left side. Instead young drivers observed three elements longer than the elderly the traffic inside the roundabout, the arm in front and the exit arm of the roundabout.

\section{New perception index}

In 1964 Neisser and Lazar [25] defined a synthetic indicator to define the average time $\mathrm{T}$ required to find a target signal within the visual scene: this time depends on the total number of observations (n) and by the average look time (t). For Neisser, the time needed to acquire the stimulus was:

$$
T=t * \frac{n}{2}
$$

By analyzing this formula, we have note that it doesn't include either the number of looks or the duration of each look. So we have decided to propose a new formula, using the gaze duration to measure the complexity of perception. Compared to the Neisser index, we have considered the same variables as, for example, the total number of gazes and the duration of each fixation, but, in our case, we have considered not the average time but the real time of fixation. Moreover, for real time of fixation (t), we have chosen to use an exponential structure. The proposed formula is:

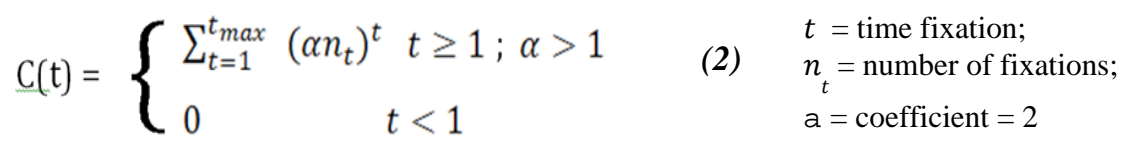


This new index provides a measure of the difficulty of perception of the same stimulus for different people, and it may be representative of the difficulties encountered by a single person in the observation of several stimuli. Then the index can be used to compare the ability of perception of the various people or to assess the complexity of a stimulus than others, for the same driver. The advantages are:

- $\quad$ real time has been considered, not the average fixation time;

- $\quad$ length of the single observation has been introduced;

- $\quad$ new index penalizes people who have difficulty to perceive a signal and maintain the view on this for long time, averting eyes from the road;

- the exponential form is better for perception in parallel [26], that drivers use to search for stimuli in complex scenes such as the road intersections.

\section{Perception of the roundabout: application of new index}

The new index has been used to assess the complexity of perception of several look zones on the roundabout travelled during the test. Road signs have been excluded from the analysis of the roundabout, because they have been ignored by drivers, so we have calculated the fixation times of each look zone, for each driver; these data are duration of the single fixation $\left(\mathrm{t}_{\mathrm{i}}\right)$ and number of fixations $\left(\mathrm{n}_{\mathrm{i}}\right)$ for several time length. The following table shows the values of new perception index, calculated for all tested drivers. $\mathrm{T}$ indicates the total time to drive inside the roundabout.

- The table shows that the most difficult element to perceive has been the previous vehicle both for elderly and young people: the average perception index is 31.82 for older drivers and 18.18 for young drivers. Driver B (young) had the greatest difficulty to perceive it: his index is 72 , and he observed the previous vehicle for $10 \mathrm{~s}$ and then for $42 \%$ of the time of the test. The Driver 8 (senior) and drivers $\mathrm{E}$ and $\mathrm{M}$ (young) have perceived this look zone quickly: these drivers have observed for 3s and their perception index is 6. Generally older drivers have observed this look zone for a mean time of $8.45 \mathrm{~s}$ and $5.36 \mathrm{~s}$ for the young ones.

- The centre island has been a difficult element to perceive, as confirmed by the perception index: 10.55 for elderly drivers and 5.45 for young drivers. This look zone has been observed for an average time of $4.18 \mathrm{~s}$ by elderly drivers and $2.73 \mathrm{~s}$ for the young ones. The driver 9 had the greatest difficulties in the perception of the central island and for him the perception index is 20. During the test, this driver has focused his gaze on the island 4 times and he observed the element for $6 \mathrm{~s}$ (25s for driving in a roundabout). Despite the drivers 6 and 7 have observed the element longer time (7 s) compared to the driver 9, for them the perception index has a lower value: the index is 14 , because the fixations had a short duration. The driver 8 had easily perceived the island and the index is 2 , 
(has observed only $1 \mathrm{~s}$ ). One of the young drivers had never seen the centre island during the test.

- Regarding the arm of the roundabout located to the right of the driver, the perception indexes are lower than those calculated for the element considered above, so this look zone is easier to understand for all the subjects tested. In this case elderly drivers have more difficulty: in fact for these drivers the average index value is 8.00, while for young drivers is 5.27. Older drivers observed the arm to the right of the roundabout for $3.45 \mathrm{~s}$ and young drivers for $2.55 \mathrm{~s}$. In this case the higher perception index is 28 (it has occurred for an older driver): in fact the driver 8 has observed this look zone for $9 \mathrm{~s}$, he looked it 5 times. The driver 4 had the least difficulty in the perception of this look zone: it was only observed for $1 \mathrm{~s}$, the perception index is 2. Two young drivers (drivers $\mathrm{E}$ and $\mathrm{H}$ ) have never seen the arm of the roundabout to their right, instead devoting more attention to the arm located to the left and traffic inside the roundabout, and this may be due to greater familiarity with this type of intersection.

- The arm of the roundabout to the left of the driver has been observed less than the arm on the right; it has been observed for an average time of $2.45 \mathrm{~s}$ by elderly drivers and for $1.27 \mathrm{~s}$ from younger ones. All drivers tested observed this look zone: $73 \%$ of young drivers have perceived it by looking for $1 \mathrm{~s}$ and the remaining three drivers observed for $2 \mathrm{~s}$. The older drivers instead observed the element for a long time, especially the Subject 2 noted the arm to the left of the roundabout for $5 \mathrm{~s}$ (for him the perception index is equal to 10). About this look zone the index is equal to 5.09 for elderly drivers is 2.55 and for young people. Regarding the arm located to the right, the one place to the left and the central island: the fixation times and perception indexes are always higher for elderly drivers than younger, it does not happen for the arm of the roundabout located in the side opposite to the vehicles within the roundabout.

- The arm of the roundabout located on the opposite side is observed for an average of $1.45 \mathrm{~s}$ by elderly drivers and $1.73 \mathrm{~s}$ for younger indexes are respectively 3.09 and 3.64. Although, on average, older drivers have lower indexes, the perception index higher were found for two elderly drivers (drivers 4 and 11) at 8, observing the opposite arm for 4 and 3 s during the test. This look zone, during the test, it is never seen by three elderly drivers and two young ones. The index of less perception has been found for drivers 1,5 and 10 and is 2 ; they have observed the opposite arm for $1 \mathrm{~s}$ during the test.

- The traffic inside the roundabout were observed for an average of $0.91 \mathrm{~s}$ by elderly drivers and their index is 1.82 and $1 \mathrm{~s}$ for the young drivers, (their Perception Index is 2). The driver 11 had the greatest difficulty to perceive this look zone, noted for $3 \mathrm{~s}$ during the test, and his index is 6 . The $45.45 \%$ (5 drivers) of older drivers tested has never seen the circulating traffic on the roundabout, as well as three young drivers.

- The exit arm of the roundabout was observed for an average of $2.27 \mathrm{~s}$ by elderly drivers and $2.36 \mathrm{~s}$ for the young ones. Young drivers had many difficulties to perceive this look zone, indeed for them the index is 5.09 and for elderly drivers is 3.27 . Drivers 2 and 3 observed the item only once during the 
Table 3: $\quad$ Look zones on the roundabout.

\begin{tabular}{|c|c|c|c|c|c|c|c|c|c|c|c|c|c|c|c|}
\hline & & \multicolumn{2}{|c|}{$\begin{array}{l}\text { Previous } \\
\text { vehicle }\end{array}$} & \multicolumn{2}{|c|}{$\begin{array}{c}\text { Arm } \\
\text { located to } \\
\text { the right }\end{array}$} & \multicolumn{2}{|c|}{$\begin{array}{c}\text { Arm } \\
\text { located to } \\
\text { the left }\end{array}$} & \multicolumn{2}{|c|}{$\begin{array}{c}\text { Arm } \\
\text { located in } \\
\text { front }\end{array}$} & \multicolumn{2}{|c|}{$\begin{array}{l}\text { Center } \\
\text { Island }\end{array}$} & \multicolumn{2}{|c|}{$\begin{array}{l}\text { Traffic } \\
\text { inside }\end{array}$} & \multicolumn{2}{|c|}{ Exit arm } \\
\hline & $\mathrm{T}$ & 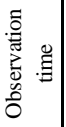 & 战 & 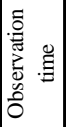 & 旅 & 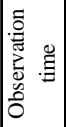 & 矛兽 & 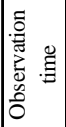 & 递 & 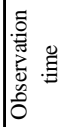 & 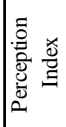 & 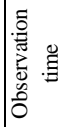 & 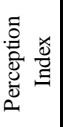 & 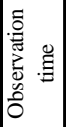 & 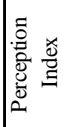 \\
\hline Driver 1 & 21 & 7 & 14 & 2 & 4 & 2 & 4 & 1 & 2 & 5 & 18 & 1 & 2 & 2 & 4 \\
\hline Driver 2 & 26 & 9 & 42 & 3 & 6 & 5 & 10 & 0 & 0 & 4 & 8 & 1 & 2 & 4 & 0 \\
\hline Driver 3 & 20 & 8 & 26 & 2 & 4 & 1 & 2 & 0 & 0 & 5 & 18 & 0 & 0 & 4 & 0 \\
\hline Driver 4 & 25 & 11 & 70 & 1 & 2 & 2 & 4 & 4 & 8 & 4 & 8 & 2 & 4 & 2 & 4 \\
\hline Driver 5 & 25 & 10 & 28 & 7 & 16 & 2 & 4 & 1 & 2 & 2 & 4 & 0 & 0 & 2 & 4 \\
\hline Driver 6 & 35 & 16 & 66 & 2 & 4 & 3 & 8 & 2 & 4 & 7 & 14 & 0 & 0 & 2 & 4 \\
\hline Driver 7 & 22 & 5 & 10 & 4 & 8 & 2 & 4 & 1 & 2 & 7 & 14 & 0 & 0 & 3 & 6 \\
\hline Driver 8 & 20 & 3 & 6 & 9 & 28 & 4 & 8 & 3 & 6 & 1 & 2 & 0 & 0 & 2 & 4 \\
\hline Driver 9 & 25 & 8 & 24 & 4 & 8 & 2 & 4 & 0 & 0 & 6 & 20 & 2 & 4 & 3 & 8 \\
\hline Driver 10 & 26 & 10 & 44 & 2 & 4 & 3 & 6 & 1 & 2 & 3 & 6 & 1 & 2 & 1 & 2 \\
\hline Driver 11 & 24 & 6 & 20 & 2 & 4 & 1 & 2 & 3 & 8 & 2 & 4 & 3 & 6 & 0 & 0 \\
\hline Mean & 24,5 & 8,45 & 31,8 & 3,45 & 8 & 2,45 & 5,09 & 1,45 & 3,09 & 4,18 & 10,6 & 0,91 & 1,82 & 2,27 & 3,27 \\
\hline Driver A & 20 & 7 & 16 & 7 & 16 & 1 & 2 & 2 & 4 & 4 & 8 & 2 & 4 & 1 & 2 \\
\hline Driver B & 24 & 10 & 72 & 5 & 10 & 2 & 4 & 2 & 4 & 2 & 4 & 2 & 4 & 3 & 6 \\
\hline Driver C & 14 & 4 & 8 & 3 & 6 & 1 & 2 & 0 & 0 & 3 & 6 & 1 & 2 & 2 & 4 \\
\hline Driver D & 15 & 7 & 22 & 2 & 4 & 1 & 2 & 1 & 2 & 0 & 0 & 0 & 0 & 4 & 10 \\
\hline Driver E & 13 & 3 & 6 & 0 & 0 & 2 & 4 & 2 & 4 & 3 & 6 & 1 & 2 & 2 & 4 \\
\hline Driver F & 17 & 5 & 18 & 2 & 4 & 1 & 2 & 3 & 6 & 3 & 6 & 0 & 0 & 3 & 8 \\
\hline Driver $\mathrm{G}$ & 15 & 4 & 10 & 2 & 4 & 1 & 2 & 2 & 4 & 4 & 8 & 0 & 0 & 2 & 4 \\
\hline Driver $\mathrm{H}$ & 15 & 4 & 10 & 0 & 0 & 1 & 2 & 3 & 8 & 3 & 6 & 1 & 2 & 2 & 4 \\
\hline Driver I & 16 & 4 & 8 & 3 & 6 & 1 & 2 & 2 & 4 & 2 & 4 & 1 & 2 & 2 & 4 \\
\hline Driver L & 18 & 8 & 24 & 2 & 4 & 1 & 2 & 0 & 0 & 3 & 6 & 1 & 2 & 3 & 6 \\
\hline Driver $\mathrm{M}$ & 16 & 3 & 6 & 2 & 4 & 2 & 4 & 2 & 4 & 3 & 6 & 2 & 4 & 2 & 4 \\
\hline Mean & 16,6 & $\mid 5,36$ & $\mid 18,2$ & $\mid$\begin{tabular}{|l|}
2,55 \\
\end{tabular} & 5,27 & 1,27 & 2,55 & 1,73 & 3,64 & 2,73 & 5,45 & 1 & 2 & \begin{tabular}{|l|}
2,36 \\
\end{tabular} & 5,09 \\
\hline
\end{tabular}

test, but for $4 \mathrm{~s}$. A young driver had the greatest difficulty in perceiving this element: Driver D observed the item for 4 s during the test with an index of 10 .

\section{Conclusions}

This study revealed that the main difference between the young and elderly drivers crossing the roundabout is the speed of execution of the manoeuvre: advancing age causes a remarkable loss of accuracy in the visual search of signals, but there is a slowing of cognitive processes involved; in fact, the fixation times needed to capture the different elements of the roundabout are higher for drivers in old age. In order to capture correctly all the stimuli necessary for driving, older drivers reduce their speed of execution of the manoeuvres, in order to make them compatible with their perceptual and 
cognitive abilities. In this paper we propose a new index to calculate the perception level of drivers for a roundabout. We compare older drivers perception index with the same calculated for a set of young drivers. Older drivers have some difficulties to perceive the previous vehicle, and the arms located at the left and at the right side respect to young people. Through this index we have tried to propose an objective measure about the use of road signs, in such a way that they represent a guide for the drivers and not an additional risk factor. In next future, we improve the index structure using the total travel time and look zone observation time, generalizing the relationship in order to compare the visual performance of drivers who travel roundabouts characterized by different geometries.

\section{References}

[1] Metzner, J .L., Dentino, A. N., Godarrd, S. L., Hay, L. H., Linnoila, M., Impairment of driving and psychiatric illness. Journal of Neuropsychiatry, 5, pp 211-220; 1993.

[2] Ball, K. Owsley, C., Sloane, M. E., Roenken D.L., Visual attention problems as a predictor of vehicle crashes in older drivers. Invest Ophthalmol Vis Sci; 34:3110-23; 1993.

[3] Lyman, S., Ferguson, S. A., Braver, E. R., Williams, A. F., Older driver involvements in police reported crashes and fatal crashes: trends and projections, 2002.

[4] Fonda, S. J., Wallace, R. B. \& Herzog, A. R., Changes in driving patterns and worsening depressive symptoms among older adults. Journal of Gerontology: Social Sciences, 56, 343-351, 2001.

[5] Guerrier, J. H., Manivannan, P., Nair, S., The role of working memory, field dependence, visual search, and reaction time in the left turn performance of older female drivers. Applied Ergonomics, 30, 109-119, 1999.

[6] Li, G. H., Braver, E. R. \& Chen, L. H., Fragility versus excessive crash involvement as determinants of high death rates per vehicle-mile of travel among older drivers. Accident Analysis and Prevention, 35: 227-235, 2003.

[7] Hills, B. L., Vision, visibility, and perception in driving. Perception, 9, 183216, 1980.

[8] Sivak, M., The information that drivers use is it indeed $90 \%$ visual?, Perception, 25, pp. 1081-1089, 1996.

[9] Vaa, T., Impairment, diseases, age and their relative risks of accident involvement: Results from meta-analysis, 2003.

[10] Marshall S. C., The Role of Reduced Fitness to Drive Due to Medical Impairments in Explaining Crashes Involving Older Drivers, Traffic Injury Prevention, 9: 4, 291-298, 2011.

[11] Kline, D. W., Scialfa, C. T., Sensory and perceptual functioning: basic research and human factors implications, 1997.

[12] Dobbs, B. M., Medical Conditions and Driving: A Review of the Literature, 2005. 
[13] Burns, P. C., Navigation and the mobility of older drivers, The Journal of Gerontology, 54 (1), pp. S49-S55, 1999.

[14] Castro, C., Horberry, T., The Human Factors of transport signs, 2005.

[15] Crassini, B., Brown, B., Bowman, K., Age related changes in contrast sensitivity in central and peripheral retina. Perception, 17: 315-332, 1988.

[16] Butler, K. M., Zacks, R. T., Henderson, J. M., Suppression of reflexive saccades in younger and older adults: age comparison on an antisaccade task. Memory Cognit, 27(4): 584-591, 1999.

[17] Dewar, R. E., Kline, D. W., Swanson, H. A., Age differences in the comprehension of traffic sign symbols. Transp. Res. Rec., 1456:1-10, 1994.

[18] Abbate, C., Luzzatti, C., Vergani, C., Matrix test: speed and accuracy of visual search in aging. G. Gerontol 55: 11-20, 2007.

[19] Owsley, C. Ball, K., Identifying correlates of accident involvement for the older driver. Human Factors, 33, 583-595, 1991.

[20] Fancello, G., Stamatiadis N., Pani E., Fadda P., Wilkinson, Are Older Drivers different in the Us And Italy?, "Urban Transport XIV” Conference Proceedings 2008.

[21] Hakamies-Blomqvist, L., Older drivers - a review, VTI rapport 497a, 2004.

[22] Fancello, G., Analisi sperimentale degli incidenti causati da guidatori anziani: un approccio multidimensionale. Ingegneria Ferroviaria, 59(1), 4756, 2004.

[23] Fancello, G., Pinna C., \& Fadda P., The vision of roundabout by elderly drivers, in Neville A. Stanton (eds) "Advances in Human Aspects of Road and Rail Transportation”, CRC Press Taylor \& Francis Group, ISBN 13: 978-0-9796435-5-2; ISBN 10: 0-9796435-5-4, 2012.

[24] Kline, D. W., Buck, K., Sell, Y., Bolan, T., Dewar, R. E., Older observers’ tolerance of optical blur: age differences in the identification of defocused text signs. Human Factors, 41(3): 356-364, 1999.

[25] Neisser U., Lazar, R. Searching for novel targets. Perceptual and motor skills, 19: 427-432. 1964.

[26] Ueno, T. Visual search time based on stochastic serial and parallel processings. Perception \& Psychophysics, Vol. 3. 1968. 